\title{
Climate change impacts on aquatic phosphorus cycling: insights from one of the world's largest lakes (Lake Erie, Canada-USA)
}

\author{
SERGHEI BOCANIOV AND PHILIPPE VAN CAPPELLEN
}

University of Waterloo

Presenting Author: serghei.bocaniov@gmail.com

The five Laurentian Great Lakes (LGLs) extend over more than $1100 \mathrm{~km}$ from south to north and $1400 \mathrm{~km}$ from east to west. The LGLs truly form inland seas, sharing many similarities with their marine counterparts, in particular in terms of differentiation between nearshore and offshore processes, Coriolis-induced circulation, physical dynamics and biogeochemical cycling of nutrients. However, their smaller size and depth, and their complete enclosure by land, more tightly couples large lakes' biogeochemistry to watershed-derived fluxes of nutrients and other chemical constituents, as well as to mesoscale atmospheric forcings. Because of their smaller size and greater accessibility, they also tend to be monitored more closely and at finer spatial and temporal resolution. Thus, the LGLs can serve as model systems to improve our understanding of ongoing climate-driven impacts on the biogeochemical cycling of phosphorus $(\mathrm{P})$ that may also be relevant to marine systems, especially coastal areas. We assembled a large knowledge and data base on the world's best studied LGL, Lake Erie, to characterize and predict the in-lake P transformation and transport processes and their responses to climate change. Lake Erie covers $26,700 \mathrm{~km}^{2}$ and was severely impacted by cultural eutrophication in the 1960s. Water quality improved dramatically from the early 1970s to mid-late 1990s. However, since the late 1990s Lake Erie has been showing signs of accelerated reeutrophication despite the continued decline and stabilization of the external $\mathrm{P}$ inputs. The reasons for this re-eutrophication are not currently understood. To provide an analytical framework to test hypotheses about the the drivers of the post-1990s changes in trophic state of the lake, we constructed comprehensive hydrologic and $\mathrm{P}$ mass budgets. We quantified the internal $\mathrm{P}$ loadings for the entire lake and for each of its three basins, taking into account the characteristic time scales for $\mathrm{P}$ transport in the lake and $\mathrm{P}$ delivery from its watershed. Next, we used historical time-series data on environmental conditions and climatesensitive forcings to identify how climate change modifies $\mathrm{P}$ dynamics in Lake Erie. The results of our analyses, and their implications, will be discussed during the presentation. 